\title{
Blocking Behavior of Organic Solid Phase in the Carbon Dioxide Multiphase and Multicomponent Displacement Process
}

\author{
Peng Yu $\mathbf{u}^{1,2}$ \\ ${ }^{1}$ Guangxi Colleges and Universities Key Laboratory of Beibu Gulf Oil and Natural Gas Resource Effective Utilization, Beibu Gulf \\ University, Qinzhou, China \\ ${ }^{2}$ College of Petroleum and Chemical Engineering, Beibu Gulf Universtiy, Qinzhou, China \\ Email: developoil@163.com
}

How to cite this paper: Yu, P. (2019) Blocking Behavior of Organic Solid Phase in the Carbon Dioxide Multiphase and Multicomponent Displacement Process. Journal of Power and Energy Engineering, 7, 183-189.

https://doi.org/10.4236/jpee.2019.71010

Received: December 29, 2018

Accepted: January 27, 2019

Published: January 30, 2019

Copyright $\odot 2019$ by author(s) and Scientific Research Publishing Inc. This work is licensed under the Creative Commons Attribution International License (CC BY 4.0).

http://creativecommons.org/licenses/by/4.0/

\begin{abstract}
Better dealing with carbon issues can support the management of current greenhouse gas emissions while achieving energy economic diversification and energy security. Carbon dioxide displacement has become the most acknowledged and practical method in enhanced oil recovery system. This is because of its oil sweep efficiency and ability to reduce the level of greenhouse gas emission. Nevertheless, it would lead to the organic solid phase deposition, which causes the changes of the wettability and the damages of wellbores and reservoirs. In this study, we used slim tube test and component test to research the dynamic characteristics of displacement process. In addition, the mechanism of porous media blockage was also investigated. Results show that when the displacement pressure closed to the minimum miscibility pressure, reservoir blockage in pore throat could happen. Component test characterizes that during near miscible displacement process, the components of oil sample varied obviously, the variation range of peak component carbon marks fluctuated strongly. Crude oil component differentiation could happen after carbon dioxide fully contacted with oil. Besides, the rapid extraction mechanism of aromatic hydrocarbons played a significant role in this process under such condition. The reason is that the solubility of saturated hydrocarbons to asphaltene and non-hydrocarbons is obviously weaker than aromatic hydrocarbons. Controlling the pressure is considered as an important link to prevent the occurrence of blocking in the carbon dioxide multiphase and multicomponent displacement process.
\end{abstract}

\section{Keywords}

Blocking Behavior, Organic Solid Phase, Carbon Dioxide Displacement, 


\section{Introduction}

Fossil fuel burning accounts for nearly $90 \%$ of the power provided to large industrial activities and is therefore the key contributor to greenhouse gas [1] [2] [3] [4]. Carbon Capture, Utilization and Storage (CCUS) is an effective mitigation measure for carbon dioxide emissions, and is considered as an acceptable technology that realizes the sustainable exploitation of fossil fuels while solving the carbon problem [5] [6] [7] [8]. Field trail history of carbon dioxide displacement for enhanced mining target has confirmed that it can improve oil recovery to a large extent [9] [10]. Due to the complexity of the migration and transformation of fluids in carbon-containing porous media, scholars concerned with related issues have become more and more popular in recent years. It is important to explore the multiphase and multicomponent properties of the whole flow system because they related to the management and process design of carbon problems such as utilization in oil reservoirs [11]. In particular, laboratory scale carbon dioxide flooding experiment study containing multiphase and multicomponent characteristics is the most valid way to understand the mechanisms of oil-gas-water-rock interaction during and after carbon dioxide injection process [12] [13]. However, the organic solid phase deposition may hinder carbon dioxide displacement in the enhanced oil recovery systems.

Organic solid phase deposition may exist in the whole flooding process and it would change the wettability and block reservoirs, which may cause the decrease of the oil recovery. The serious phenomenon can seriously block the pipelines, damage the region around wellbore and cutting down the capacity of surface process facilities [14] [15]. Therefore, for better management of the oilfield development, it is important to find more on the effects of the key mechanism. It was generally considered that the higher pressure, the better performance of the displacement. The researches about unfavorable factors related to carbon dioxide displacement mainly concentrated on fingering or corrosion. Several documents mentioned the problem of deposition in the carbon dioxide displacement process. However, there are few researches on the mechanism of the specific blocking behavior [16] [17]. In this research, the mechanism of porous media blockage was studied by using slim tube test and component detection on the carbon dioxide flooding process [18] [19].

\section{Experiment Part}

Slim tube displacement is mainly used for judgment of minimum miscible pressure. The tube is usually fine and long in order to permit full occurrence of dynamic miscible process, flooding in this type of tube approach nearby the perfect flooding. Viscous fingering developing is limited by the walls of the tube. It is 
supposed that fluids are mixed uniform due to small diameter of the tube and also closed to homogeneous media in the slim tube. For minimum miscible pressure measurements, the slim tube is first saturated with the oil and controls the temperature as the reservoir temperature simultaneously, the gas is then injected into the slim tube and crude oil recovery is calculated. This experiment supplied the dynamic data of displacement test and the oil samples in the flooding process. Follow the experimental test step strictly in slim tube experiment process (Figure 1) and the typical oil samples which were utilized in the test were taken from Beibu Gulf offshore oilfield. Finally, the minimum miscible pressure was measured about $30 \mathrm{MPa}$.

\section{Blockage Mechanism of Organic Solid Phase}

For explore the deposition and blockage mechanism of carbon dioxide displacement, the family component test and saturated hydrocarbon evaluation were experimented on sample source at slim tube system. As we have seen, Figure 2 characterizes the test results for saturated hydrocarbon, and the oil sample was collected from the near minimum miscible pressure environment (28 $\mathrm{MPa})$. Remove of the initial state curve (black curve), the first characteristic curve shows the composition of saturated hydrocarbons before the time node for carbon dioxide breakthrough, and also injected pore volume multiple is 0.95 at breakthrough time. The rest of the characteristic curves characterize the composition state after carbon dioxide breakthrough. From the picture we can clearly see the components of the oil sample at the initial time of carbon dioxide breakthrough and before breakthrough were similar to the initial crude oil, but the component differences become more and more obvious with the deepening of the flooding process. Obviously, the extraction effect of carbon dioxide became intense after breakthrough time, which directly resulted in the characteristic differences.

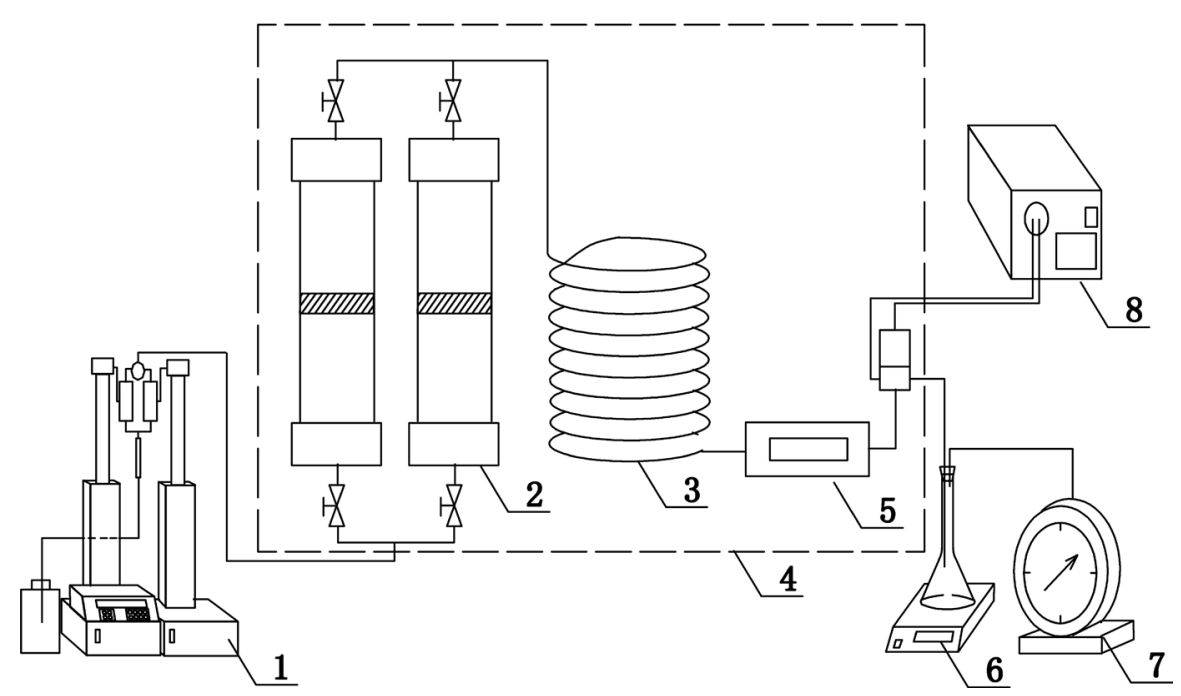

Figure 1. Schematic diagram of experimental apparatus including (1) ISCO constant speed pump, (2) oil and gas intermediate container, (3) slim tube model, (4) oven, (5) observation window, (6) balance and separation bottle, (7) gas meter, (8) back pressure valve. 
Under the condition of near miscible displacement process, the components of oil sample varied obviously, the variation range of peak component carbon marks fluctuated strongly. From the whole process, intense differentiation of crude oil is produced after oil contact with carbon dioxide fully. This situation may result in the possibility of poor phenomenon that heavy components blocked porous media. It was generally considered that the carbon dioxide displacement pressure value higher, the better the efficiency. Therefore, controlling pressure is an important link to flooding process.

Figure 3 shows the results of the family component test, the No.1 sample was collected before carbon dioxide breakthrough; the No.2 - No.9 samples were collected from the carbon dioxide-oil mixed zone; No.10 - No.14 samples were collected after carbon dioxide breakthrough.

Under the pressure of near miscible, the components feature of the oil samples

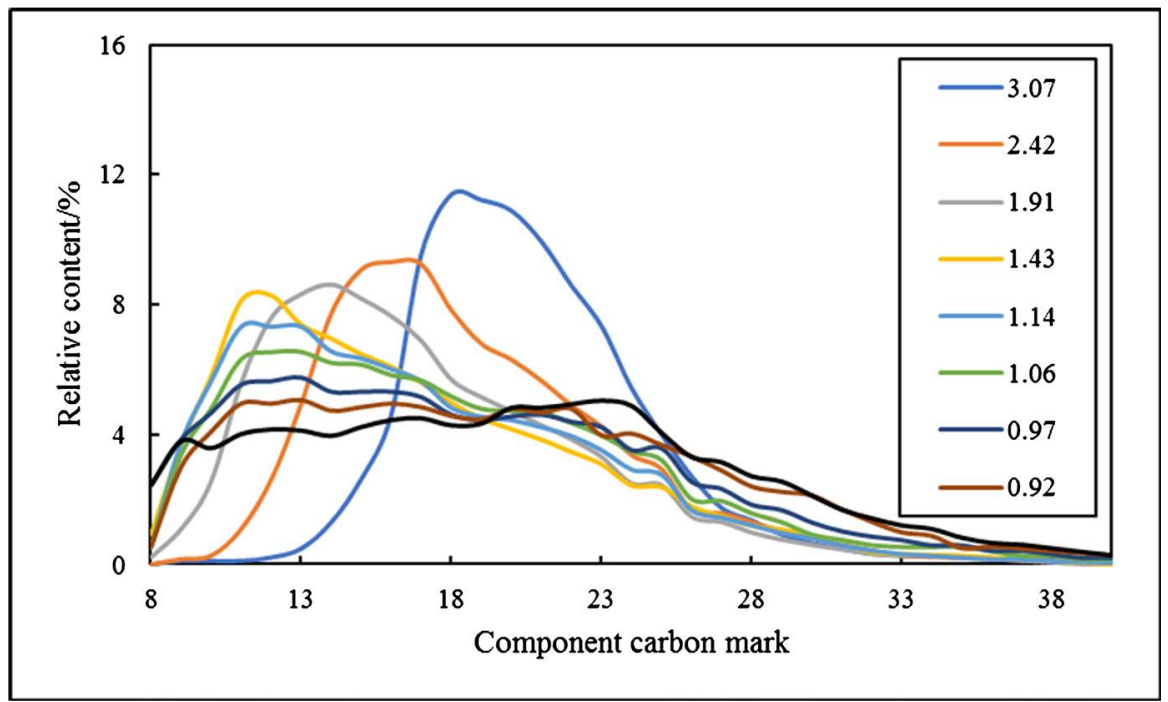

Figure 2. Saturated hydrocarbon composition of crude oil at different PVs.

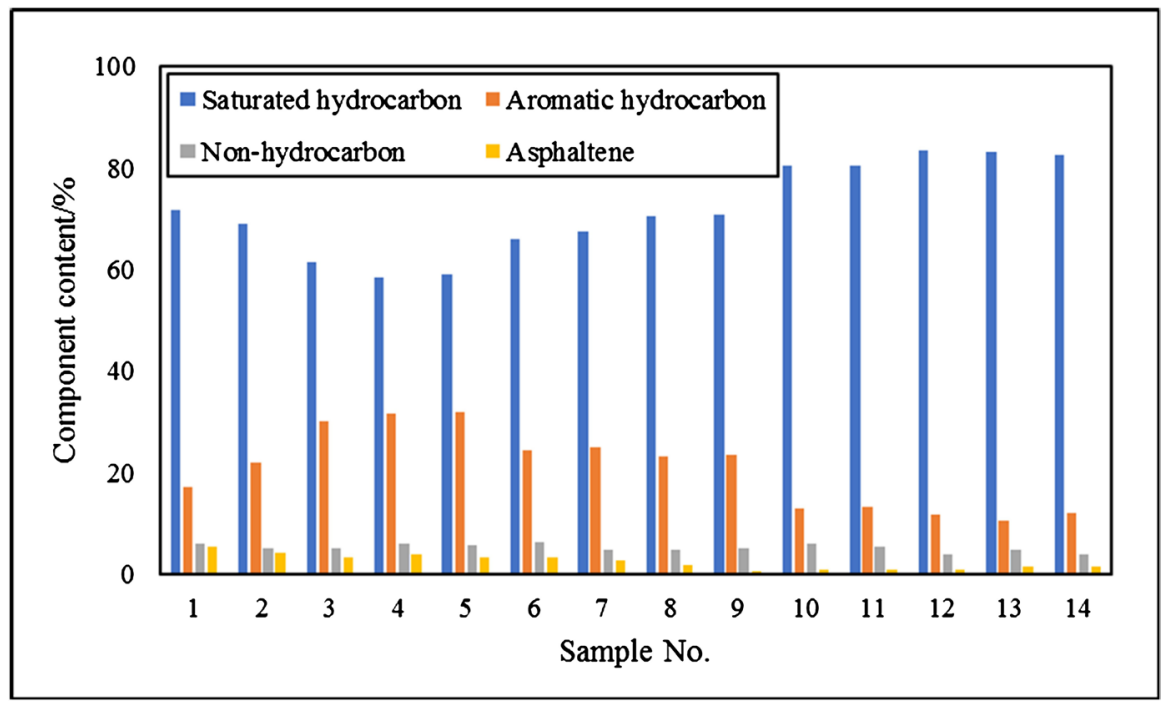

Figure 3. Component analysis results of crude oil for different samples. 
sourced at the mixed zone were obviously different from those before the carbon dioxide breakthrough, the change of components of asphaltene and non-hydrocarbon is not obvious, but the component contents of aromatic hydrocarbons greatly increased. The reason is that the solubility of saturated hydrocarbons to asphaltene and non-hydrocarbons is obviously weaker than aromatic hydrocarbons. Therefore, the rapid extraction mechanism of aromatic hydrocarbons played a major role in this process. Intense extraction effect leads to the phenomenon of asphaltene and non-hydrocarbons deposition quickly, and then blocking the throats of porous media.

\section{Conclusion}

In conclusion, when displacement pressure is nearby the minimum miscibility pressure, the probability of blockage increases obviously. Organic solid phase precipitation and deposition could be problematic in all steps of carbon dioxide flooding process. Experimental results of the intense differentiation of crude oil are produced after oil contact with carbon dioxide fully, as a result, heavy components accumulate and cause blockage at throats while light components migrate quick, which is one of the main laws of carbon dioxide displacement blockage. Therefore, controlling pressure is an important link to flooding process.

\section{Acknowledgements}

This work was financially supported by the Guangxi Natural Science Foundations (2016GXNSFBA380180, 2017GXNSFAA198105), the Guangxi Education Department Scientific Research Project (2017KY0792), the Beibu Gulf University Scientific Research Project (2016PY-GJ09), the Opening Project of Guangxi Colleges and Universities Key Laboratory of Beibu Gulf Oil and Natural Gas Resource Effective Utilization (2016KLOG01, 2017KLOG25).

\section{Conflicts of Interest}

The author declares no conflicts of interest regarding the publication of this paper.

\section{References}

[1] Haszeldine, R.S. (2009) Carbon Capture and Storage: How Green Can Black Be? Science, 325, 1647-1652. https://doi.org/10.1126/science.1172246

[2] Dai, Z. (2018) Heterogeneity-Assisted Carbon Dioxide Storage in Marine Sediments. Applied Energy, 225, 876-883. https://doi.org/10.1016/j.apenergy.2018.05.038

[3] Gale, J. (2004) Geological Storage of $\mathrm{CO}_{2}$ : What Do We Know, Where Are the Gaps and What More Needs to Be Done? Energy, 29, 1329-1338. https://doi.org/10.1016/j.energy.2004.03.068

[4] Gershenzon, N.I. (2015) Influence of Small-Scale Fluvial Architecture on $\mathrm{CO}_{2}$ Trapping Processes in Deep Brine Reservoirs. Water Resources Research, 51, 8240-8256. https://doi.org/10.1002/2015WR017638 
[5] Celia, M.A. (2017) Geological Storage of Captured Carbon Dioxide as a Large-Scale Carbon Mitigation Option. Water Resources Research, 53, 3527-3533. https://doi.org/10.1002/2017WR020841

[6] Singh, H. and Islam, A. (2018) Enhanced Safety of Geologic $\mathrm{CO}_{2}$ Storage with Nanoparticles. International Journal of Heat and Mass Transfer, 121, 463-476. https://doi.org/10.1016/j.ijheatmasstransfer.2017.12.152

[7] Soltanian, M.R. (2017) Dissolution Trapping of Carbon Dioxide in Heterogeneous Aquifers. Environmental Science \& Technology, 51, 7732-7741. https://doi.org/10.1021/acs.est.7b01540

[8] Song, C.W. (2015) A Study on Potential Geologic Facility Sites for Carbon Dioxide Storage in the Miocene Pohang Basin, SE Korea. Journal of the Geological Society of Korea, 51, 53-66. https://doi.org/10.14770/jgsk.2015.51.1.53

[9] Monteagudo, J.E.P., Lage, P.L.C. and Rajagopal, K. (2001) Towards a Polydisperse Molecular Thermodynamic Model for Asphaltene Precipitation in Live-Oil. Fluid Phase Equilibria, 187-188, 443-471. https://doi.org/10.1016/S0378-3812(01)00566-0

[10] Zekri, A.Y. and Shedid, S.A. (2004) The Effect of Fracture Characteristics on Reduction of Permeability by Asphaltene Precipitation in Carbonate Formation. Journal of Petroleum Science and Engineering, 42, 171-182. https://doi.org/10.1016/j.petrol.2003.12.009

[11] Manceau, J.C. (2015) Two-Phase Flow Properties of a Sandstone Rock for the $\mathrm{CO}_{2} /$ Water System: Core-Flooding Experiments, and Focus on Impacts of Mineralogical Changes. Water Resources Research, 51, 2885-2900. https://doi.org/10.1002/2014WR015725

[12] Sun, Y., Li, Q., Yang, D. and Liu, X. (2016) Laboratory Core Flooding Experimental Systems for $\mathrm{CO}_{2}$ Geosequestration: An Updated Review over the Past Decade. Journal of Rock Mechanics and Geotechnical Engineering, 8, 113-126. https://doi.org/10.1016/j.jrmge.2015.12.001

[13] Moreno, R.Z., Santos, R.G., Okabe, C. and Schiozer, D. J. (2011) Comparison of Residual Oil Saturation for Water and Supercritical $\mathrm{CO}_{2}$ Flooding in a Long Core, with Live Oil at Reservoir Conditions. J. Porous Media, 14, 699-708. https://doi.org/10.1615/JPorMedia.v14.i8.40

[14] Thawer, R., Nicoll, D.C.A. and Dick, G. (1990) Asphaltene Deposition in Production Facilities. SPE Production Engineering, 5, 475-480. https://doi.org/10.2118/18473-PA

[15] Al-Maamari, R.S.H. and Buckley, J.S. (2003) Asphaltene Precipitation and Alteration of Wetting: The Potential for Wettability Changes during Oil Production. SPE Reservoir Evaluation \& Engineering, 6, 210-214. https://doi.org/10.2118/84938-PA

[16] Khataniar, S., Kamath, V.A., Patil, S.L. and Chandra, S. (1999) $\mathrm{CO}_{2}$ and Miscible Gas Injection for Enhanced Recovery of Schrader Bluff Heavy Oil. International Thermal Operations/Heavy Oil Symposium, Bakersfield, 17-19 March 1999, SPE-54085-MS. https://doi.org/10.2118/54085-MS

[17] Brush, R.M., Davitt, H.J., Aimar, O.B., Arguello, J. and Whiteside, J.M. (2000) Immiscible $\mathrm{CO}_{2}$ Flooding for Increased Oil Recovery and Reduced Emissions. SPE/DOE Improved Oil Recovery Symposium, Tulsa, 3-5 April 2000, SPE-59328-MS. https://doi.org/10.2118/59328-MS

[18] Buckley, J.S. and Wang, J. (2002) Crude Oil and Asphaltene Characterization for Prediction of Wetting Alteration. Journal of Petroleum Science and Engineering, 33, 195-202. https://doi.org/10.1016/S0920-4105(01)00189-9 
[19] Ibrahim, H.H. and Idem, R.O. (2005) A Method for Evaluating the Kinetics of n-Heptane-Induced Asphaltene Precipitation from Various Saskatchewan Crude Oils during Light Hydrocarbon Flooding. Fuel, 84, 311-314.

https://doi.org/10.1016/j.fuel.2004.08.007 